\title{
Identización: la construcción discursiva del individuo
}

\section{Identization: the discursive construction of individual}

\author{
Carmen Gómez Redondo \\ Universidad de Valladolid \\ carmen.gomez.redondo@gmail.com
}

Recibido: 3 de mayo de 2011

Aprobado: 18 de julio de 2011

\section{Resumen}

La educación cada vez más corre de la mano de la enculturación, si bien nunca han sido ámbitos contrarios, la postmodernidad se ha encargado de romper las barreras y la pureza disciplinaria a favor de un enfoque globalizado. Se hace por tanto necesario dibujar sombras que configuren la idea de individuo y por tanto de identidad. En el siguiente trabajo se presenta una ontología de la construcción del individuo, es decir, la identización, a través de un nuevo enfoque que antepone la creatividad del proceso frente a procesos de apropiación. Entendemos aquí identidad como un todo más complejo que la adopción roles establecidos, la mismidad es más que la frontera con la otredad.

Palabras Clave: Educación, individuo, sociedad, identización.

Gómez Redondo, C. 2011: Identización: la construcción discursiva del individuo. Arte, Individuo y Sociedad, 24(1), 21-37

\begin{abstract}
Education runs increasingly from the hand of inculturation, but it has never been opposed fields, postmodernity has been responsible for breaking down barriers and the disciplinary purity in favor of a global approach. It is therefore necessary to draw shadows that shaped the idea of individual and therefore of identity. The following paper presents an ontology of the construction of the individual, ie identization through a new approach that puts the creativity of the process compared to processes of appropriation. We understand this identity as a whole more complex than adopting established roles, the self is more than the border with otherness.
\end{abstract}

Key Words: Education, individual, society, identization.

Gómez Redondo, C. 2011: Identization: the discursive construction of individual. Arte, Individuo y Sociedad, 24(1), 21-37

Sumario: 1. Introducción, 2. Construcción de la mismidad y la otredad, 3. (Con)formación de la identidad: la praxis contínua del entorno, 4. Identidad y tiempo: la necesidad del recuerdo, 5. Conclusiones Referencias 


\section{Introducción}

Hablar de educación en el siglo XXI resulta asombrosamente innovador. El término ha cambiado sus usos, educación no refiere ya a institución oligárquica, acumulación, jerarquía, espacio cerrado ni tiempos vitales; la educación actual refiere a un proceso en construcción, a nuevos descubrimientos, a lo relacional, multidimensional, creativo, social y sobre todo individualizador.

Saber ser se configura como primera premisa en el desarrollo con el entorno. Esta afirmación, a primera vista puede resultar dicotómica, el individuo contra la sociedad, dibujándose éste casi como una frontera y no como un espacio. Esta segmentación de espacios ha dado lugar a conceptualizaciones de la identidad un tanto deterministas, conformaciones a partir de lo que la sociedad permite ser al fin y al cabo, a la construcción casi como una significación por contraste, ser lo que no son ellos. Remite esta idea al modelado del individuo por presión, una materia formada a partir de las distintas presiones externas.

Este determinismo responde a la idea de identificación, aludiendo a una pseudolibertad de elección entre múltiples opciones dadas desde el entorno. La identificación sería aquí como un traje; un traje con medidas estandarizadas, y donde el individuo se prueba la talla en la que mejor cabe. El mundo interpretado al que alude Rilke y en el que no nos sentimos del todo a gusto. Así, en cierto modo hablar de identidad es hablar únicamente de actitudes en sociedad, de pluralidad y polimorfismo desde la normalización, la identidad postmoderna tan solo se diferenciaría de la premoderna en la ampliación de la gama de identidades o roles.
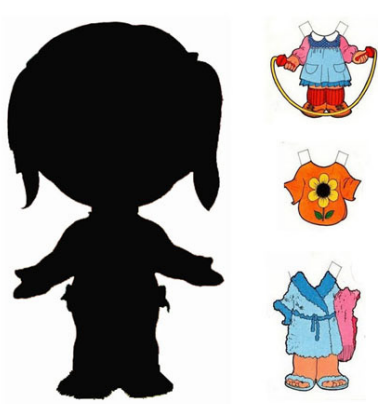

Identidad: el individuo se enfrenta a la sociedad adoptando los roles que se le ofrecen.

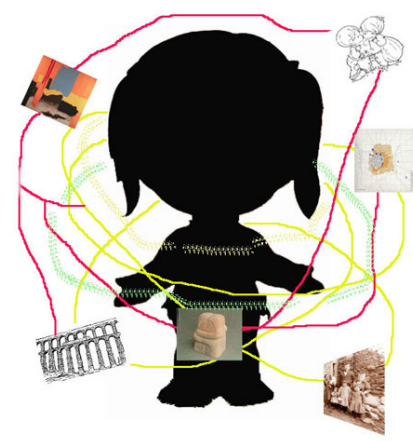

Identizacion: el individuo crea su identidad en un microcosmos multisustancial.

Figura. 1. Identidad e identización

Sin embargo, entendemos aquí la identidad como un todo complejo multimatérico, donde los límites no se presentan tan solo actitudinales, sino afectivos, relacionales, apropiacionales. La identidad pretende aquí un microcosmos de ideas, afectos, actitudes, creencias, valores, categorías, recuerdos, objetos...Una miscelánea relacional a modo de sinapsis. Un microcosmos con su propia teoría del big-bang, un continuo movimiento y mutación, de sustancias y relaciones, es por tanto, 
que deberíamos hablar más propiamente de identización ${ }^{1}$ que de identidad, una potencialidad frente a la factividad.

Así pues, la identización remite casi automáticamente a una construcción arquitectónica (Eisner, 2004), a una delimitación de espacios, al bocetaje; a lo artístico y a lo creativo, en cuanto a ámbito en el que proceso y producto se solapan en el espacio y el tiempo, “... la construcción y revisión de la propia identidad no es una tarea que pueda darse (nunca) por finalizada..." (Rodrigo y Medina, 2006:126). La creación de la identidad vendría a ser como una casa en continua reforma, un lugar cuyas paredes tienen ruedas, pudiendo cambiar sentido, y dirección, dibujando, continuamente, espacios nuevos.

\section{Construcción de la mismidad y la otredad}

Para poder considerar la relación entre individuo y sociedad como una evolución y no como mutaciones o saltos cualitativos, es necesario comprender una estructura común a todos los puntos contextualizadores, a todas las sociedades entendidas como pluralidad dentro de la unicidad a la que referimos con el término sociedad. Así pues debe entenderse una arché-sociedad, como la propuesta por Morin, que se define como "un modelo universal de sociedad (...), que se ha mantenido varias decenas de millares de años a través de la diáspora planetaria" (Morin, 2003:69). En esta concepción universalista sociedad e individuo son a la vez medio y fin, la sociedad permite la realización del individuo y el individuo perpetúa la sociedad (Morin, 2003). Atendemos pues a una relación holográmica en cuanto a que sociedad e individuo se autocompletan, la sociedad está en el individuo y el individuo en la sociedad; una relación recursiva, refiriendo a la sincronía en su formación, de la interrelación de los individuos se produce sociedad, constituyendo un todo organizador, cuyas cualidades emergentes retroactúan sobre los individuos. Los individuos producen cualidades emergentes, generalizándose en sociedad, la sociedad, por su parte, controla y regula las interacciones entre individuos, produciéndose así una tercera relación dialógica e incluso antagonista entre individuo y sociedad (Morin, 2003).

Si bien Morin hace referencia, en esta arché-sociedad al individuo, podríamos decir que éste, en su concepción más subjetiva, apartándose de formulaciones teóricas y universalistas, es un invento contemporáneo. Esta idea un tanto provocadora pretende reseñar su antítesis, la concepción premoderna, de un todo social compuesto de individuos, entendidos como partículas, como fracciones iguales que componen la generalidad. Así pues, al referir al individuo premoderno es necesario hacer referencia a la sociedad, caracterizada por la rigidez de su estructura, en cuyas cualidades el individuo es identificado, no se identifica, no existen opciones, divergencias, misceláneas ni diversidad. La antigua sociedad es unívoca y proporciona un "mayor sentimiento de seguridad sobre el futuro de uno mismo al precio de un escaso margen de libertad personal" (Rodrigo et al, 2006:129). El individuo se encuentra ante una única posible identidad y es presionado para identificarse con lo que se espera de él, siendo muy costoso emocionalmente intentar salirse de estos parámetros.

Sin embargo y aunque la estructura universalista propuesta por Morin siga soportando esta organización humana, la rigidez de los márgenes cualitativos ha ido 
disminuyendo a lo largo del tiempo dando lugar a la actual concepción postmoderna donde individuo es equivalente a nada, no existen equidades ni comparaciones, cada individuo es único, subjetivo, desapareciendo así las partículas premodernas, para formar granos, motas, botones, pellizcos... Una individualidad que suma, una heterogeneidad que mantiene equilibro, casi inefable, para formar sociedad; de tal modo que sociedad e individuo siguen manteniendo esa relación holográmica, pero ahora la sociedad, tal y como entiende Giddens ha sido institucionalizada "La modernidad se ha de entender en un plano institucional; pero los cambios provocados por las instituciones modernas se entretejen directamente con la vida individual y, por tanto, con el yo" (Giddens, 1995:9), aunque esta institucionalización no supone una redefinición, ni una vuelta a la rigidez en los márgenes estructurales premodernos, significa una pluralización del orden, no existe una entidad superior, sino que se diversifica y jerarquiza, atendiendo a una multidimensionalidad de la realidad, presentándose como una volubilidad ante el individuo.

Tal vez sea necesario analizar de nuevo, la relación entre individuo y sociedad, no desde esta relación de antinomía casi durkheimiana, sino desde un punto de vista procesual, de cómo se forma la sociedad desde la pequeña escala, desde el individuo, generándose identidades, valores, normas, actitudes cada vez en mayor grado compartidos y consensuados hasta llegar a conformar una sociedad, de este modo, y gracias al carácter autorreferencial de los procesos sociales, podremos hablar de ontología social desde el proceso de socialización (García y García, 2001)

Así pues, el proceso de socialización del individuo denota/conforma el sistema ontológico de la sociedad (Searle, 1997) en primer lugar, a través de la asignación de funciones ya que se entiende que los objetos sociales poseen una función consensuada y ratificada por los miembros. En el proceso de socialización el individuo genera una función propia, formándose así en el sujeto un binomio funcional, en base al sistema objetivo/subjetivo. "El proceso de socialización, en correspondencia con la ontología social, consiste en la identificación y el reconocimiento (aceptación) de las funciones asignadas a las construcciones sociales, adquiriendo competencia de observador y usuario social" (García et al, 2001:99). En segundo lugar a través de una intencionalidad colectiva, patente en toda interacción humana. La simbolización, en cuanto al componente abstracto de la sociedad como son valores, normas, creencias es un constructo colectivo, y por lo tanto el empleo de esta simbolización conlleva implícitamente una intencionalidad colectiva, un deseo de compartir entre individuos, y sobre todo, saberse parte, ser usuario y por tanto saberse poderoso para actuar sobre esas simbolizaciones colectivas. "Socializarse, consiste pues, en adquirir intencionalidad colectiva, ejercitar la actividad mental de ponerse en el punto de vista del nosotros y participar en la intencionalidad social" (García et al, 2001:99). Y finalmente en la creación de instituciones y categorías a nivel individual, es decir, generar sistemas de reglas que rigen el comportamiento social. Este sistema es dinámico y multidimensional, pudiendo gestionarse de manera abstracta, abolirse, crear nuevas categorías, relacionarlas, aceptadas, e incluso interferir en el grado de autenticidad, es decir, diferenciar entre convención y regla. 


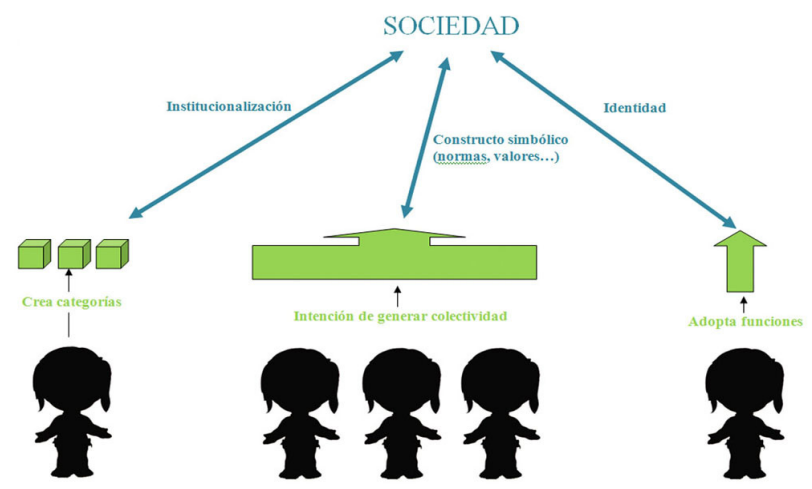

Figura. 2. Relación holográmica individuo y sociedad

Por lo tanto, el individuo en su proceso de socialización, en su conformación sociocognitiva reproduce/configura el sistema y las categorías de la sociedad en la que se inscribe, de este modo, podría decirse que individuo y sociedad forman una analogía estructural. Si bien, esta concepción un tanto determinista hay que entenderla dentro del relativismo de la posmodernidad, de la subjetividad y de la diversidad que se propugna. Podríamos decir que el sistema propuesto pretende ser la generalidad, el orden que precede a la casuística; no conviene tal vez, recurrir a la idea de estructura ya que puede remitir de nuevo a este determinismo, sino que conviene considerarlo como un sedimento común desde la particularidad.

\section{3. (Con)formación ${ }^{2}$ de la identidad: la praxis contínua del entorno}

La identidad como un núcleo fijo, coherente y estable que describe la definición ilustrada ha sido superada por la visión posmoderna del individuo y su conformación desde un punto de vista social y cultural, ya que "...el ser humano es un ser social por naturaleza y no se construye a sí mismo en el aislamiento". (Rodrigo et al, 2006:126). Así pues la identidad posmoderna es polimorfa, dinámica y sobre todo, desde el punto de vista aquí tratado, cultural. A modo de síntesis, definir la identidad como un proceso de dotación de significados respecto al entorno: "Las identidades son fuentes de sentido para los propios actores y por ellos mismos son construidas mediante un proceso de individualización" (Castells, 2001:28-29).

Al entender la identidad como proceso con un movimiento dinámico cabe entender su extensión a lo largo de la vida, es decir, la identidad no se compone en un único lapso vital, sino que está en continua construcción. El individuo está continuamente analizando su entorno e interiorizándolo para adaptarse de la mejor manera posible a él. Esta interiorización, o creación de sentido como la define Rodrigo “...es una operación compleja cognitiva y emotiva en la que interviene el bagaje enciclopédico (Background) de una persona y que podríamos denominarlo su universo referencial" (Rodrigo, 2003:299). Así pues, de las palabras del autor se puede extraer una dualidad complementaria, lo cognitivo y lo emotivo; de este modo, el individuo no 
interpreta el entorno desde lo puramente racional, sino que lo acerca y lo aleja de sí a través de lo afectivo: "El "espacio mental" establecerá la "mismidad" y "otredad" o alteridad, mientras que el "espacio sentimental" establecerá los límites de mi afiliación emocional y de mis procesos de identificación simbólica". (Rodrigo, 2003:298)

Respecto de esta interpretación cognitiva y emocional, el individuo construye su universo referencial, a través de los contextos que el entorno dispone ante el individuo, éste experimenta y dota de sentido, otorga significados a una realidad que pasa a ser subjetiva, experimentada y filtrada. El universo referencial, el bagaje enciclopédico al que refiere Rodrigo, no responde a una realidad objetiva, sino a una apropiación que nace de lo social pero cobra sentido en lo individual y en esta individualidad se convierte, efectivamente, en universo, en espacio heterogéneo,en miscelánea humana:

Evidentemente acometer la descripción del contenido del universo referencial de una persona es una tarea realmente dificil, a menos que esquematicemos una realidad muy compleja. Nos encontramos con un contenido heteróclito y homogéneo, paradójico y coherente, fijo y mutable que está compuesto de sentido común y de conocimientos científicos, de razón y de pasión, de valores y de datos, de logos y de mhytos, de juicios y de prejuicios, de estereotipos y de un largo etcétera (Rodrigo, 2003:299).

La conceptualización de la identidad del individuo, en términos de conformación, es decir, de estructura constructiva, se antoja una tarea hercúlea, analizar cualidades cuantitativas y cualitativas de ésta precisaría de una hermenéutica del individuo que no conviene al caso de este estudio. Es por ello que en este punto afrontaremos dicha conformación como una ordenación, así, recurriendo a la metáfora iniciada al inicio de este artículo, puede que no sepamos cuántas habitaciones se formarán, ni cómo de grandes serán, ya que ambos criterios se forman en base a particularidades, pero entendemos que existe un orden, ámbitos prediseñados y paredes que configurarán la creación de espacios.

Así pues, para una correcta enmarcación y el alcance de nuestro objetivo, se hace necesario comprender la conformación de la identidad del individuo, en un primer ordenamiento, como una dualidad, lo cognitivo y lo afectivo (Castañero y Cáceres, 2008), funcionando desde su separación conceptual como unidad, es decir, si bien ambos sistemas se diferencian aquí, para su análisis, en la realidad funcionan junto a otros sistemas como un todo, entrelazado sin fronteras. Lo cognitivo y lo afectivo a modo de metáfora, funcionan como un líquido de color naranja, conocemos que su origen se encuentra en el magenta y amarillo, pero si intentamos separarlo desaparecerá el naranja. En éste líquido de color se nos presentan las diferentes estructuras: categorías, valores, creencias..., como esponjas empapadas de líquido suspensorio, y de nuevo, pierden su esencia si se separan de él.

De lo cognitivo y lo afectivo de la identidad, se estudiarán a continuación dos efectos de relevancia en lo cultural: estereotipos y valores, entendidos como formas significativas de la relación del individuo con su entorno, composiciones individuales, personalizadas, pero que reflejan este proceso de conformación de la identidad retroalimentándose con el sistema cultural. 


\section{Locus cognitivos: estereotipos y prejuicios.}

Para facilitar la comprensión de estos conceptos antes de profundizar más en ellos se hace necesario introducir un eje articulador, una definición más antropológica de la mente humana, que aporte luz a este nivel de ordenación del universo referencial. Este eje es lo que Wallace denominó mazeway:

El raciocinio de cada hombre abarca en un determinado momento, como producto de su experiencia, una única imagen mental de un complejo sistema de objetos dinámicamente relacionados, que incluye el cuerpo en el que éste está alojado, diversos otros objetos circundantes y a veces hasta el cerebro mismo. Esta compleja imagen mental es un mazeway. Su contenido consiste en un número extremadamente grande se asociaciones o residuos cognitivos de percepciones. Es usada por su poseedor como una verdadera y más completa representación de las características operativas del mundo "real". El mazeway puede ser comparado al mapa de un gigantesco laberinto, con una leyenda o clave elaborada y muchas intercalaciones. (Wallace, 1963:27-28).

El mazeway, más ambicioso aún que el mapa conceptual, ya que el mazeway conecta entorno e individuo, es el sistema equivalente al sistema cultural, la estructura mental que reproduce la estructura cultural. Es la forma del $\mathrm{orden}^{3}$, si cada individuo debiera construir una red tridimensional de vínculos entre $\operatorname{cosas}^{4}$ que lo conforman, se podría observar (o no, ya que es puramente relativo a cada cultura e individuo) algo así como una nube de conexiones, donde variarían la cantidad de enlaces unidos a cada cosa, así como su grosor y longitud; además habría cosas más cercanas entre ellas, o más lejanas, o unidas con el mismo tipo de conexión e incluso capas, burbujas, líquidos base y un sinfín de recursos que ayudarían a comprender esta complejidad. Así pues, desde aquí, entendemos el mazeway más como una red tridimensional que como un mapa bidimensional pero compartiendo la base de estructura organizativa compleja y ligada a diversas dimensiones del individuo como unidad.

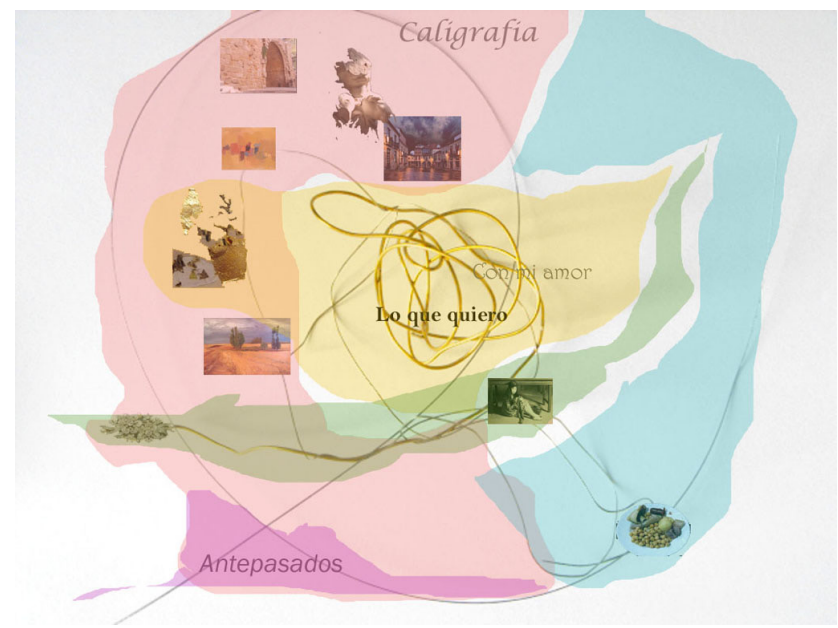

Figura. 3. Interpretación plástica de un mazeway 
Este mazeway tiene como principal función componer una imagen de lo que se podría denominar procesos de ordenación, es decir, del cómo clasificar, categorizar, asociar o disociar las distintas experiencias con el entorno. Empezando por el término más globalizador, como si de un gran angular se tratara, se encontrarían los locus cognitivos, entendidos como lugares de intelección, más amplios que las categorías y que de hecho contienen categorías relacionadas, locus responde así a un nivel metacognitivo, los lugares o parcelas en que podríamos dividir el mazeway, pero sin entenderlas rígidas ni estáticas, sino más bien caleidoscópicamente, así pues podríamos hablar de locus de lo afectivo, locus de lo social y de tantos otros que refieran a clasificaciones de este nivel.

En un segundo nivel de concreción aparecerían las categorías o grupos, que obtendrían su imagen mental en las listas, es decir, la enumeración de cosas asociadas o unidas bajo ciertos criterios o etiquetas comunes a todas ellas. Las diversas cualidades y cantidades de categorías son fenómenos puramente culturales, aunque es cierto que todas las culturas poseen categorías. De nuevo, no cabe una imagen de categoría estática, sino que se deforman y amoldan, se superponen en las concepciones, se jerarquizan y se complementan a medida que se adquieren nuevas experiencias a cerca de las cosas que conforman el mazeway. Así, como ejemplo desde lo artístico, el cuadro de Pablo Picasso, Guernica, puede pertenecer a una categoría denominada obras pictóricas, a subcategorías, en cuanto a la técnica o utilización de colores, pero también puede pertenecer a categorías colectivas o individuales, es decir, puede pertenecer a la categoría de memoria histórica de la Guerra Civil Española o bien a la categoría de cosas que me dan miedo.

Este tipo de procesos operan clasificando y ordenando la realidad percibida, es decir conformando y mutando, lo que Rodrigo (2003) denomina universo referencial, que además está en continuo crecimiento. Estos procesos de ordenación sirven además como base para un proceso mucho más complejo y en el que el individuo debe poner en juego todo este universo referencial, este proceso al que referimos es la creación de situaciones de seguridad ante futuribles. Es decir ante la presencia de situaciones desconocidas ( ción que recibe y no siempre del modo más acertado, produciéndose clasificaciones del tipo de los prejuicios y los estereotipos. Recogemos aquí la definición de ambos que da Rodrigo:

Un prejuicio es simplemente una creencia u opinión preconcebida. Es decir, es una idea que se tiene antes de que la situación nos demande su elaboración”. Del estereotipo añade, "se trata de aplicar una concepción a una circunstancia, a una realidad determinada, a partir de un molde prefigurado, sin tener demasiado en cuenta si se trata del molde adecuado o no para interpretar dicho fenómeno (Rodrigo, 2003:300)

De esta idea de prejuicio se puede extraer un fondo creativo, realizado por el propio individuo en base a sus procesos cognitivos y a su bagaje cultural, podría decirse que siguiendo una lógica personal y empapado de un componente afectivo (Navas, 1997) (Fernández, 2005). En cambio, el estereotipo se forma a partir de la colectivización de estos prejuicios, es decir, el estereotipo responde, no a una elaboración propia, sino que posee un claro componente cognitivo externo (Navas, 1997) 
(Fernández, 2005), una adquisición cultural, una enculturación. Queda patente en ambas, su carácter simplificador, homogeneizador, su factura grosso modo, que tiene como fin clasificar la realidad de forma rápida, calmar la ansiedad del descontrol del entorno, quedando implícito en esta función un gran margen de error, un sesgo a modo de impronta.

Sin embargo, los estereotipos y los prejuicios siguen siendo utilizados, tal vez, como propone Fernández (2005) sea porque además de su función simplificadora y clasificadora del entorno cumple otras funciones como justificación ante acciones contra determinados grupos sociales, y de forma más general, como justificación de argumentos sobre acontecimientos culturales más complejos; además de forma más individual pueden facilitar la explicación de características y comportamientos personales y finalmente, como corroboración de la importancia de este apartado, una función sustentante de lo que se ha dado en denominar "identidad social", aquí denominada "identidad cultural", que sería una parte esencial del autoconcepto. Y añade "En este sentido las verbalizaciones que hacemos sobre nosotros mismos pueden estar relacionadas con la pertenencia a determinados grupos sociales en los que nos incluimos" (Fernández, 2005:187)

\section{Ordenación de lo afectivo: los valores.}

Se hace difícil obtener una definición concreta y consensuada que resuma el concepto de valor, tal vez sea precisamente éste el punto problemático, su carácter abstracto y transversal ${ }^{5}$ obstaculiza la concreción de todas las cualidades y atribuciones en una única definición, es por ello que muchos autores han focalizado sus investigaciones en la clasificación de los distintos valores; de este modo, primeramente, antes de atender a clasificaciones, se tratará de dar forma al concepto.

El concepto de valor aparece como marca, asociado a la relevancia atribuida a ciertos objetos reales, el valor es selectivo. Aparece como adjetivación, no es una entidad completa en sí misma, sino que está sujeta al objeto; es la abstracción que da sentido de concreción.

Así pues, los valores atribuidos aparecen, al igual que los estereotipos, como producto cultural (Rokeach, 1973) y concreto de las clasificaciones de lo afectivo dentro del mazeway, coincidiendo con Fontal "actúan como base de la identidad individual y colectiva, pues son compartidos por conjuntos sociales en las culturas de las que surgen y en las culturas que los estudian" (Fontal, 2003:44). En una primera dimensión de análisis se pueden diferenciar pues, diferentes ámbitos de aplicación de los valores, diferentes sistemas, objetivos, apriorísticos, puros y por tanto compartidos y ratificados y los valores individuales, subjetivos, particularizantes y empapados de experiencias (Frondizi, 1995).

Una segunda dimensión de análisis atiende a su esencia (Scheler, 2001:145), y en cuanto a ésta pueden ser: positivos o negativos, independientemente de la percepción subjetiva de un contravalor, los valores positivos deben ser, y los negativos no deben ser (Scheler 2001:146). Este mismo autor, defensor del modelo objetivista y dentro de su concepción polarizada, dibuja una jerarquía abstracta donde impone dos niveles de valores, superior e inferior, el nivel superior, se caracteriza por su durabilidad y generalidad, entendida esta como la imposibilidad de división. El nivel inferior, por 
lo tanto se caracteriza por todo lo contrario, sirviendo los valores superiores como fundamento de los inferiores. En un nivel mayor de concreción el autor propone un sistema de valores donde los valores religiosos culminan la jerarquía, son valores superiores; por debajo de ellos, se sitúan los valores espirituales, relacionados con el conocimiento puro. Scheler (2001) aplica, en este caso, una subdivisión que contiene a los valores estéticos, jurídicos e intelectuales. Por debajo de este segundo nivel, estarían los valores vitales y finalmente, como valores más bajos aparecen los valores del agrado.

De lo visto hasta aquí queda implícita una concepción de los valores objetivista, dejando de lado lo subjetivo, remitiendo continuamente, a una estructura superior, despojando al individuo de su humanidad, estandarizando el comportamiento humano y subordinándolo a ese orden superior. Sin embargo, otros autores han ido aportando, a lo largo de la historia, diferentes clasificaciones de los valores, en base a la subjetividad. Así el modelo subjetivista, entiende los valores como productos humanos, generados en un momento determinado, éstos son volubles y relativos, por ello cada investigación aporta nuevas categorías, elimina otras y jerarquiza ámbitos, la axiología se dibuja, desde la subjetividad, como un caleidoscopio que gira según las necesidades culturales.

Rokeach (1973) plantea los valores como determinantes de las acciones individuales, incluso con un carácter reflexivo, considerada ésta una de las grandes aportaciones del autor:

De algún modo, la originalidad de la teoría sobre valores de este autor se sitúa en el hecho de atribuir a los valores un cariz autoreflexivo; los valores en tanto que autoconcepciones que un sujeto tiene de sí mismo, de los demás y del mundo social adquieren el carácter de sistema de creencias personal mediatizado por el contexto social que ayudan al sujeto a tener un sentido de identidad, ya no sólo a nivel individual, sino también de su propia comunidad social (Garzón y Garcés, 1989: 365) ${ }^{6}$

Define dos tipos de valores, los instrumentales, es decir, aquellos que sirven como medio para la consecución de ciertos fines, o bien entendidos como fines en sí mismos, es decir, valores terminales.

Profundizando en el ámbito experiencial de los valores y tocando la factividad frente a la potencialidad anteriormente expuesta, y con ello, evidenciando la capacidad de generar significado proponemos aquí una escala aplicada al patrimonio, en la cual el valor se entiende como "cualidad añadida que los individuos atribuyen a ciertos objetos que los hacen merecedores de aprecio" (Ballart, 1996:215). Respecto a esta definición podrían diferenciarse en un primer análisis dos tipos de valores: materiales e inmateriales, los primeros relativos, a sus cualidades tangibles e intrínsecas ${ }^{7}$ y por ello gestionables desde un punto de vista económico y los segundos, relativos a sus cualidades extrínsecas, culturales, vinculantes y por lo tanto, valores en los que recae el peso de la denominación de patrimonio. Si bien esta clasificación dicotómica tan solo sirve de manera inicial para diferenciar la naturaleza de los valores y por tanto el ámbito de gestión, la mayoría de los autores, debido a la inseparabilidad de ambas naturalezas, elaboran clasificaciones donde ambas se combinan sin jerarquías. 
Es interesante recordar aquí la clasificación de valores de Riegl (1987), que aunque superada en lo que a interpretación del patrimonio refiere, ofrece una clasificación dicotómica en base al proceso clave de transmisión; así existen valores de antigüedad y de contemporaneidad, haciendo hincapié en la importancia de la enculturación del patrimonio, distingue el autor, dentro de los valores rememorativos el valor de antigüedad, histórico, y rememorativo intencionado; y dentro de los valores de contemporaneidad el valor instrumental y el artístico (Riegl, 1987). Desde una perspectiva interpretativa más contemporánea Ballart establece, en base a la clasificación propuesta por Lipe ${ }^{8}$, tres categorías: valor de uso relativo a su utilidad, valor formal en cuanto a sus cualidades materiales y valor simbólico-significativo en cuanto a su capacidad evocadora y asociativa (Ballart, 1997). Fontal amplía la clasificación de Ballart describiendo cinco categorías: el valor de uso asociado a la utilidad; valor material en cuanto a sus cualidades físicas; simbólico o relacional relativo a su carácter evocador y comunicativo; valor histórico en cuanto a su capacidad reveladora del pasado y valor emotivo asociado a la afectividad para con el bien (Fontal, 2003)
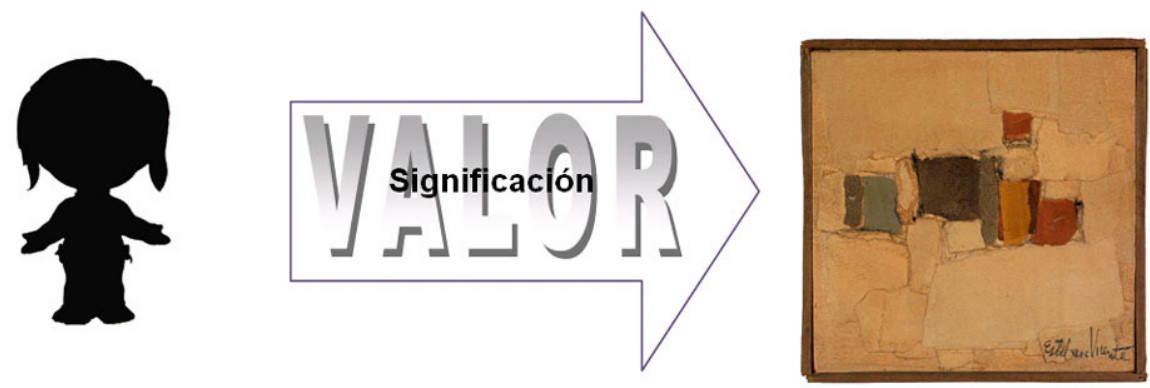

Figura 4. Significación a través de la valoración

Entendemos pues, desde los niveles más abstractos a los más concretos, que los valores atienden a marcas y relevancias atribuidas a objetos, cualidades, conceptos, realidades, es decir, atienden a otro modo de clasificación de la realidad desde lo afectivo. Es por ello que las últimas investigaciones han determinado enmarcar el ámbito de lo afectivo dentro del ámbito de lo cognitivo, desestancándose desde su concepción axiológica y relacionándose con otros sistemas cognitivos del individuo (Garzón y Garcés, 1989). De esta relación con lo cognitivo emana la relatividad cultural de los valores (en cuanto a atribución y clasificación). El entorno cultural determina la configuración del mazeway, y por tanto, aunque la sustancia cognitiva ${ }^{9}$ se suponga universal a los seres humanos, cada cultura elaborará sus propios subsistemas y categorías, así: "Será la propia historia y la cultura de cada comunidad social la encargada de configurar esos sistemas de valores que darán a entender lo que los individuos particulares y los colectivos valoran o infravaloran en un momento histórico dado" (Garzón et al. 1989:369) 


\section{Identidad y tiempo: la necesidad del recuerdo}

La heterogeneidad y dinamicidad que, hasta ahora, han caracterizado el concepto de identidad aquí representado contrastan con la singularidad del término. Del mismo modo, los diversos autores tratados se hacen eco de esta paradoja, empleando en sus títulos y definiciones el término identidad, para matizar en los cuerpos, sobre las identidades. Así pues, identidad hace referencia a unicidad, frente a la pluralidad de los términos hasta ahora empleados como identidades, identificaciones o roles. Impera, por lo tanto, una necesidad de subjetividad, el individuo se concibe como único y homogéneo pese a la diversidad de identidades que adopta en el tiempo y en el entorno "...el sentido se organiza en torno a una identidad primaria (es decir, una identidad que enmarca al resto), que se sostiene por sí misma a lo largo del tiempo y el espacio" (Castells, 2001:29)

El individuo no se percibe desmembrado, múltiple o multidimensional, sino que se percibe como un todo coherente:

Al igual que otros aspectos existenciales de la seguridad ontológica, los sentimientos de identidad del yo son a la vez robustos y frágiles. Frágiles, porque la biografía del individuo conserva reflejamente en la mente es sólo una "historia" entre otras historias posibles que podrían ser narradas acerca de su evolución en cuanto al yo; robusta, porque a menudo se mantiene con suficiente seguridad un sentimiento de identidad del yo como para capear tensiones o cambios importantes del medio social en el que se mueve la persona (Giddens, 1995:75)

Este equilibrio entre pluralidad y unicidad puede explicarse a través de lo que Giddens (1995) considera una biografía individual, y que recuerda en su estructura a la narratividad propuesta por Bruner (1999). Así pues, estructuralmente la biografía se configura como una linealidad, un cuerpo único que se extiende en el espacio y en el caso del texto biográfico, en el tiempo. En esta estructura se integran diversidad de conceptos que se coordinan para formar ideas más complejas e interrelacionadas, o aisladas, donde la única coherencia aparece de la unidad lineal, de forma análoga la biografía individual "Deberá incorporar constantemente sucesos que ocurren en el mundo exterior y distribuirlos en la "historia" continua del yo" (Giddens, 1995:74). El individuo reflexiona sobre su mismidad y su identidad a través de su biografía:

Parece evidente, entonces, que la habilidad para construir narraciones y para entender narraciones es crucial en la construcción de nuestras vidas y la construcción de un "lugar" para nosotros mismos en el posible mundo al que nos enfrentamos (Bruner, 1999:59)

Surge aquí un matiz implícito, importante aunque sin presencia patente, el transcurso del tiempo, y por ende, la necesidad del recuerdo. Así, de la propuesta de Giddens (1995), se desprende un transcurso, narrado desde el presente; una identidad pasada que es recordada para conformar el discurso de la unicidad identitaria del individuo. Es necesario, por lo tanto, tratar aquí el recuerdo y, teniendo presente el tema que se trata así como las tesis de Halbwachs (2004), seguiremos un enfoque cultural, 
entendiendo que los individuos articulan su memoria en base a la pertenencia a través de estructuras sociales como el espacio, tiempo y lenguaje, cuya sujeción reside en lo tangible.

Retomando las palabras de Giddens (1995) se pude comprender la relación individuo y entorno a lo largo del tiempo, los sucesos se incorporar a la historia del individuo, vuelve entonces a colación la idea del individuo como sistema, como entidad relacional conformado por diversidad de cosas, entre ellas, en lo que ahora ocupa, los recuerdos.

El recuerdo nace como una construcción, como una sinapsis entre el entorno y el individuo; y como a Gulliver ${ }^{10}$ lo sujeta al suelo, a la realidad y a su historia, de tal modo que "sólo lo que ha sido aprendido puede ser recordado" (Marcilla, Alcalde y Ramiro, 1993: 196). Esta sinapsis es ideada como reunión de la dualidad interior/exterior, individuo/entorno hasta tal punto que se rechaza lo puramente generado desde el interior como recordable:

"En consecuencia, no hay percepción sin recuerdo. Y, a la inversa, no existe recuerdo alguno que pueda ser considerado como puramente interior, es decir, que sólo se conserve en la memoria individual." (Halwbachs, 2004:319)

Así pues el recuerdo viene a ser una imagen mental de lo aprendido en el pasado, refiriendo tanto a situaciones, conceptos, palabras, objetos, sentimientos, emociones... Es decir todo aquel background al que refiere Rodrigo (2003), y que por ser traídos al presente se convierten en recuerdos. Esta presencia los hace, además, característicos, los define y determina, los hace vívidos, a modo de aparición espontánea. Unidades inseparables e imperceptibles por segmentos. Es decir, el recuerdo aparece como una imagen mental única y por tanto en el proceso de evocación aparece como tal; una aparición, un fantasma que tan pronto está, como desaparece. No se conforma de pequeñas estructuras de las que se pueda tirar para traer el recuerdo, definido literalmente: "Se trata pues, de sensaciones sumamente simples, "no compuestas", aunque no podamos reflexionar sobre sus elementos y el modo como se combinan, antes que la sensación no se haya producido" (Halbwachs, 2004:142). Y sin embargo, pese a este proceso interno del individuo, el recuerdo depende exclusivamente del exterior, de lo denominado por el autor como los marcos de la memoria (Halwbachs, 2004) dibujados desde las diferentes claves interpretativas, que suponen tiempo, espacio y lenguaje. De este modo el acto de recordar queda sujeto al presente y al entorno actual. Así pues, para recordar es necesario asociar con el exterior, o como enunciaban Marcilla et al (1993), debe ser aprendido para poder ser recordado. El entorno funciona pues, como un plomo, una piedra de la que sujetar el hilo del recuerdo, un resorte que lanza a la mente hacia la imagen mental, hacia la sensación halbwachsiana. Esta asociación entre recuerdo y entorno, se produce a través de una relación de semejanza ya sea cognitiva o emotiva (Halbwachs, 2004), es decir, ese maridaje puede asentarse sobre conceptos o sobre sensaciones y emociones. 


\section{Conclusiones}

Como proponíamos en la introducción de este trabajo la identidad se establece como una identización, no tan sólo en lo que afecta a la pluralidad de identificaciones como propone Baeza (2000), sino en su conformación y en su naturaleza procesual.

Hemos definido el proceso de identización como parejo a la formación de la sociedad, entendiendo que la interpretación común del entorno genera una sociedad. Este tipo de proposición constructivista frente a la determinista, supone además dejar de lado concepciones dicotómicas, individuo frente a sociedad, dónde el individuo asume significados y roles estandarizados. Bajo este punto de vista, a la luz del determinismo, la posmodernidad tan solo ofrece diversidad de identidades a las que adaptarse.

Frente al modelado de la identidad determinista, se propone una identidad generativa, una creación en continuo movimiento que no se basa en polimorfismos sino en "polisustancialismos" coherentes a lo largo del tiempo, la identidad a lo largo del tiempo cobra sentido en la narración, como un único relato, como una construcción discursiva, donde la mutación es el único rasgo perenne.

La identidad, en un intento de fotografía instantánea, se presenta como un microcosmos un mazeway, una estructura, desestructurada con diferentes sustancias en suspensión, sustancias que se relacionan en base a cogniciones y afectos, sinapsis que vinculan desde la experiencia y para la experiencia. El individuo por lo tanto encuentra su fin en su creación del entorno, en la asociación al medio, interior y exterior fluyen en una amalgama porosa.

Hablamos pues educativamente de un verdadero aprendizaje, de una reinterpretación del entorno, de la creación de la identidad, de (con)formación, en cuanto a un dibujo del camino a medida que se anda, la identización es por tanto aquí, un vagar, un paseo, en el que el individuo elige a cada paso cuál será el siguiente, que verá o quién caminará a su lado, un aprendizaje desde lo interno hacia lo externo y donde la educación es la base sustancial, el medio por el que el individuo consigue ser un único individuo, la técnica del paseo, el movimiento.

\section{Referencias}

Baeza, J.A. (2000). Los caminos invisibles de la realidad. Ensayo de sociología profunda sobre los imaginarios sociales. Chile: Sociedad Hoy.

Ballart Fernández, J. (1997). El patrimonio histórico y arqueológico: valor y uso, Barcelona: Ariel.

Ballart, J., Fullora, J. \& Petit, M.A. (1996). El valor del Patrimonio Histórico. Complutum Extra, II (6), 215-224.

Bruner, J. (1995). Desarrollo cognitivo y educación. Madrid: Morata.

(1999). La educación, puerta de la cultura. Madrid: Visor.

Castells, M. (2001). El Poder de la Identidad. México: Siglo XXI.

Dipietro, S. (2004). El concepto de socialización y la antinomía individuo/sociedad en Durkheim. Revista Argentina de Sociología, 2 (003), 95-117. 
Eiser, J.R. (1980). Cognitive social Psichology. London: McGraw-Hill.

Eisner, E. W. (2004). El arte y la creación de la mente. El papel de las artes visuales en la transformación de la conciencia. Barcelona: Paidós.

Fernández, A. (2005). Multiculturalidad en contextos educativos y de desarrollo: Relevancia de variables psicosociales. Revista Electrónica de Investigación Psicoeducativa y Psicopedagógica, 1 (5-3),181-204.

Fontal, O. (2003). La educación patrimonial: teoría y práctica para el aula, el museo e internet. Gijón: Trea.

Fontal, O. \& Valle, R.E. (2007). Del museo al aula: disfrutar la cultura desde la diversidad. En Calaf, R., Fontal, O. \& Valle, R. E. (Coords.), Museos de arte y educación: Construir patrimonios desde la diversidad (361-385). Gijón: Trea.

Frondizi, R. (1995). ¿Qué son los valores? Introducción a la axiología. México: Fondo de Cultura Económica.

García, J. \& García, A. (2001). Teoría de la Educación II. Procesos primarios de formación del pensamiento y la acción. Salamanca: Universidad de Salamanca.

Garzón, A. \& Garcés, J. (1989). Hacia una conceptualización del valor. 7. En Mayor, J. \& Pinillos J.L. (Eds.), Tratado de Psicología general. Madrid: Alhambra.

Geertz, C. (1994). Conocimiento local. Ensayos sobre la interpretación de las culturas. Barcelona: Paidós.

Giddens, A. (1995). Modernidad e identidad del yo. El yo y la sociedad en la época contemporánea. Barcelona: Península.

Goodenough,W.H. (2004). Rethinking "Status" and "Rol”. Toward a General Model of the Cultural Organization of Social Relationships. En Banton, M. (Ed.), The Relevance of Models for Social Anthropology (1-22). London: Routledge.

Halbwachs, M. (2004). Los marcos sociales de la memoria. Barcelona: Anthropos.

Hall, S. \& Du Gray, P. (Comp.) (2003). Cuestiones de identidad cultural. Buenos Aires: Amorrortu.

Harris, M. (2003). El desarrollo de la teoría antropológica. Una historia de las teorías de la cultura. Madrid: Siglo XXI.

Ibañez, J. (1990). Prólogo. En Maffesoli, M., El tiempo de las tribus (9-19). Barcelona: Icaria.

Lipe, W. (1984). Value and meaning in cultural resources. En Cleere, H. (Ed.), Approaches to the archaeological heritage. A comparative study of the world cultural resource management systems (1-11). Cambridge: Cambridge University Press.

Marín, R. (1976). Valores, objetivos y actitudes en educación. Valladolid: Miñon.

Marcilla, A. Alcalde, C. \& Ramiro, P. (1993). Organización, recuerdo y olvido. Estrategias del uso de la memoria. En Navarro J.I. (Coord.), Aprendizaje y memoria humana. Aspectos básicos y evolutivos (171-207). Madrid: McGrawHill. 
Morin, E. (2003). El método. La humanidad de la Humanidad. V. La Identidad humana. Madrid: Cátedra.

Navas, M. S. (1997). El prejuicio presenta un nuevo rostro: puntos de vista teóricos y líneas de investigación recientes sobre un problema familiar. En Revista de Psicología Social, 12 (2), 201-237.

Olmo, M. (1994). Una teoría para el análisis de la identidad cultural, Arbor: Ciencia, Pensamiento y Cultura, (579), 79-98.

Riegl, A. (1987). El culto moderno a los monumentos. Madrid: Visor.

Rilke, R. M. (1999). Elegías de Duino. Madrid, Hiperión.

Rodrigo, M. (1998). Las estrategias identitarias: entre el ser y el hacer. Afers Internacionals, (43-44), 11-15.

(1999). Comunicación intercultural, Barcelona: Anthropos.

(2003). Interculturalidad y medios de comunicación: el caso de Cataluña. En Zariquiey, R. (Ed.), Realidad multilingüe y desafio intercultural. Ciudadanía, política y educación (295-321). Lima: Pontificia Universidad Católica del Perú.

Rodrigo, M. \& Medina, P. (2006). Posmodernidad y crisis de identidad, IC: Revista Científica de Información y Comunicación, (3), 125-146.

Rodrigo, M., Gayá, C. \& Oller M.T. (1997). De la identidad cultural a las identidades culturales. Revista Reflexiones, (57), 3-23.

Rockeach, M. (1973). The nature of human values. New York: Free Press.

Sánchez, A. (2005). Ética, Barcelona: Crítica.

Scheler, M. (2001). Ética, Madrid: Caparrós.

Searle, J. R. (1997). La construcción de la realidad social. Barcelona: Paidós.

Spindler, G.D. (2006). La transmisión de la cultura. En Velasco H.M., García F.J. \& Díaz, A. (Eds.), Lecturas de Antropología para educadores. El ámbito de la antropología de la educación y de la etnografía escolar (205-241). Madrid: Trotta.

Wallace, A.F. (1963). Cultura y personalidad. Buenos Aires: Paidós.

\section{Notas}

1. Si bien el término identización responde a un neologismo ya utilizado por algunos autores (Baeza, 2000), en el que se entiende el proceso de identización como un proceso de creación de identidad en base a una relación dicotómica con la sociedad. Entendemos aquí la identización como un proceso creativo, en cierto modo autogenerado y también aprendido. Un proceso inconcluso con una conformación sustancial más allá de roles sociales.

2. El empleo de paréntesis viene aquí justificado por la intención de reseñar el doble proceso de formación y conformación, es decir, una suerte de autogeneración sin modelos, remite pues, de nuevo a un proceso creativo. 
3. Orden entendido dentro de lo cultural, es decir la forma en que cada cultura ordena su entorno.

4. Por cosas entendemos toda clase de entidades individuales que cada individuo pueda concebir. Este concepto tan amplio es idóneo para entenderlo como descripción tanto de objetos, ideas, sentimientos y emociones enumeradas de una en una, desde la particularidad.

5. Algunos autores como Ballart, Fullora y Petit, 1996, apuntan a la asignación de los valores al campo de la filosofía, si bien, entendemos que dichos valores son atribuciones humanas, concernientes, en su estudio a los diversos ámbitos en los que aparece.

6. Garzón y Garcés analizan en castellano la obra de Rokeach y otros autores como medio para una posible conceptualización del valor. Clasifican al autor dentro de las corrientes subjetivistas, y destacan su innovación al proponer los valores como productos culturales.

7. Estos valores fueron denominados por Baudrillard valores de ambiente (Baudrillard, 1988).

8. Lipe distingue cuatro categorías del valor: Asociativo-simbólico, informativo, estético y económico. (Lipe, 1984). Ballart utiliza como base estos principios y los generaliza desde la concepción de Lipe, referida únicamente al patrimonio arqueológico, hacia todo bien patrimonial.

9. Sirva esta expresión para hacer referencia a procesos cognitivos comunes a todas las culturas pese a variaciones estructurales abstractas.

10. Cabe utilizar al personaje de Jonathan Swift como metáfora del anclaje del individuo a su entorno. 